\title{
Operação de filtros orgânicos utilizados no tratamento de águas residuárias de suinocultura
}

\author{
Marcos A. de Magalhães', Antonio T. de Matos ${ }^{2}$, Wilson Denículi \& Ilda de F. F. Tinoco ${ }^{2}$
}

\begin{abstract}
RESUMO
Este trabalho consistiu no estudo da operação de filtros orgânicos, utilizando-se bagaço de cana-de-açúcar e serragem de madeira, como materiais filtrantes. O experimento foi conduzido na Área Experimental de Hidráulica, Irrigação e Drenagem do Departamento de Engenharia Agrícola, da Universidade Federal de Viçosa. Colunas de 1,0; 1,3; 1,6; 1,9 e 2,0 $\mathrm{m}$ foram preenchidas com esses materiais, para filtragem de água residuária da suinocultura (ARS), o que foi realizado em três replicatas. Para monitoramento da perda de carga nos filtros, foram instalados piezômetros. O tempo de operação dos filtros, até que a taxa de filtração passasse a ser menor que $0,2 \mathrm{~L} \mathrm{~m}^{-2} \mathrm{~s}^{-1}$, foi de 100 a $150 \mathrm{~min}$. As taxas de remoção de sólidos em suspensão (SS) e de sólidos totais (ST) foram, respectivamente, de 90 a $99 \%$ e de 43 a 57\%, utilizando-se filtros de serragem de madeira, e de 81 a $96 \%$ e de 50 a $56 \%$, usando-se filtros de bagaço de cana-deaçúcar. A eficiência de filtragem aumentou com o passar do tempo, ocasionada pela obstrução gradativa dos poros e pela retenção de sólidos da ARS nas colunas filtrantes. A altura da coluna filtrante não alterou significativamente a eficiência dos filtros na remoção de SS.
\end{abstract}

Palavras-chave: filtragem, materiais filtrantes, tratamento de resíduos

\section{Operation of organic filters used for treatment of swine wastewater}

\begin{abstract}
This work consisted of study of operation of organic filters utilizing sugarcane bagasse and sawdust as filtering material. An experiment was carried out at the Experimental Area of Hydraulics, Irrigation and Drainage of the Department of Agricultural Engineering, Federal University of Viçosa. Columns with 1.0, 1.3, 1.6, 1.9 and $2.0 \mathrm{~m}$ of height were filled with the organic material for the swine wastewater filtering, with three replicates. Piezometers were installed for the head loss monitoring. The filters were operated during 100 to $150 \mathrm{~min}$ until the filtering rate was less than $0.2 \mathrm{~L} \mathrm{~m}^{-2} \mathrm{~s}^{-1}$. Removal rates between 90 to $99 \%$ for suspended solids (SS) and 43 to $53 \%$ for total solids (TS) were reached, using sawdust filters, and 81 to $96 \%$ for SS and 55 to $56 \%$ for TS, using canetrash filters. The filtration efficiency increased with time, due to gradual obstruction of the pores in the filter columns. The height of filter column did not alter significantly filter efficiency in removing SS.
\end{abstract}

Key words: filtering, filtering materials, residue treatment 


\section{INTRODUÇÃO}

Por ser concentradora de dejetos em pequenas áreas, a suinocultura moderna de produção animal de forma confinada, gera grandes volumes de águas residuárias de alto potencial poluidor para o solo, o ar e a água, já que se trata de efluente rico em sólidos em suspensão e dissolvidos, matéria orgânica, nutrientes (nitrogênio e fósforo, dentre outros), agentes patogênicos, metais pesados e sais diversos (Matos et al., 1997).

Dentre as opções de que se dispõe para tratamento/disposição de águas residuárias da suinocultura (ARS) está a do aproveitamento agrícola, tendo em vista o elevado valor fertilizante que esses líquidos apresentam: entretanto, em razão da grande quantidade de material sólido em suspensão nessas águas residuárias e mesmo após ela ter passado por tanque de sedimentação primária, unidades de tratamento subseqüentes permanecem recebendo cargas orgânicas ainda muito elevadas, o que concorre para aumento dos custos de implantação e operação do sistema, como um todo. Freqüentemente tem-se verificado muitos problemas de entupimento de bombas, tubulações e, sobretudo, de emissores, quando se faz opção pela disposição dos efluentes do sedimentador no solo.

Para uso de ARS em fertirrigação, o risco de entupimento de gotejadores pode ser considerado baixo, moderado ou severo, respectivamente, para concentrações de sólidos suspensos menores que $50 \mathrm{mg} \mathrm{L}^{-1}$, entre 50 e $100 \mathrm{mg} \mathrm{L}^{-1}$, e superiores a $100 \mathrm{mg} \mathrm{L}^{-1}$ (Bucks et al., 1979). De acordo com Leon \& Cavallini (1999) a concentração relativa de sólidos nos efluentes, admitida para um bom funcionamento do sistema de irrigação por gotejamento, deve ser inferior a $50 \mathrm{mg} \mathrm{L}^{-1}$.

A ação mecânica de eliminação dos sólidos em suspensão (SS) por filtração se baseia-se no princípio de que um meio poroso pode reter impurezas de dimensões menores que as dos poros da camada filtrante (Povinelli \& Martins, 1973), porém esses mecanismos de remoção são temporários ou finitos, tendo em vista a obstrução gradativa dos poros do leito filtrante, com conseqüente aumento da perda de carga no filtro (Magalhães, 2002).

Um meio filtrante ideal deve ser constituído de partículas de diâmetro e tipo de material que proporcionem melhorias significativas na qualidade do efluente das colunas filtrantes e retenham o máximo possível de sólidos. Materiais filtrantes mais finos deverão proporcionar a geração de um efluente mais depurado; entretanto, produzirão, também, maior perda de carga nas camadas superiores da coluna filtrante proporcionando, assim, pequeno período de operação do filtro.

Embora as vantagens do uso de materiais orgânicas em filtros para ARS já tenham sido comprovadas (Brandão et al., 2000 e Lo Monaco et al., 2002), pouco se sabe sobre critérios e parâmetros de projeto e sua operação.

Com a realização deste trabalho objetivou-se avaliar a operação de filtros orgânicos de diferentes alturas, constituídos por serragem de madeira e bagaço de cana-de-açúcar triturado, e sua eficiência no tratamento de águas residuárias de suinocultura quanto à remoção de sólidos totais e em suspensão.

\section{MATERIAL E MÉTODOS}

O experimento foi conduzido nas dependências da Área Experimental de Hidráulica/Irrigação e Drenagem do Departamento de Engenharia Agrícola da Universidade Federal de Viçosa, sendo os filtros construídos com tonéis metálicos de 0,58 m de diâmetro, interligados, no caso de colunas de maior altura que a original do tonel, nos quais foram acondicionados os materiais orgânicos, perfazendo colunas filtrantes de 1,$00 ; 1,30 ; 1,60 ; 1,90$ e 2,10 m de altura; na extremidade inferior dos tonéis fez-se um furo para adaptação, na parte externa, de registro, por onde se coletou o efluente filtrado.

Para preenchimento das colunas de filtração foram utilizados dois tipos de resíduo orgânico: o bagaço de cana-deaçúcar triturado e a serragem de madeira, previamente secados ao ar e, em seguida, triturados, utilizando-se o Desintegrador/Picador-Moedor (DPM), nº 01, equipamento constituído de 4 conjuntos de 3 martelos (total de 12 martelos), peneira com malha de $10 \mathrm{~mm}$ e motor de $5 \mathrm{cv}$; depois de triturados, os materiais orgânicos foram peneirados em diferentes malhas, de forma a se obter duas faixas granulométricas: 5,0-8,0 mm e 2,5-3,0 mm.

A escolha das faixas granulométricas para o material filtrante foi baseada nos resultados obtidos por Lo Monaco et al. (2004), que recomendaram o uso de granulometrias entre 2,0 e 3,0 mm, por se tratar das que proporcionaram maior filtração sem, contudo, aumentar em demasia a perda de carga no sistema.

Na base de cada coluna de filtração foi instalado um sistema de drenagem, constituído por tubos de PVC de $50 \mathrm{~mm}$ de diâmetro, perfurados (furos de 2,0 mm de diâmetro). Para evitar a passagem de partículas do material filtrante e entupimento dos drenos, uma camada de $20 \mathrm{~cm}$ de material grosseiro (partículas do mesmo material orgânico, nos diâmetros de 5 a $8 \mathrm{~mm}$ ), foi disposta no fundo dos recipientes, cobrindo os drenos; sobre a camada de material mais grosseiro, dispôs-se a camada de material filtrante, com granulometria de 2,5 a 3,0 mm, cuja altura foi variável, conforme esquema experimental apresentado na Figura 1. Para evitar que ocorresse rápida colmatação da camada superficial do filtro, colocou-se sobre a coluna filtrante, uma camada de $20 \mathrm{~cm}$ de altura, constituída de material de mesma granulometria do material que foi colocado junto aos drenos (5,0-8,0 mm).

Para cada coluna de filtração foram instalados dois piezômetros, conforme apresentado na Figura 1, a fim de se quantificar e monitorar, ao longo do tempo, a perda de carga na coluna filtrante. Esses piezômetros foram instalados nas transições entre as camadas filtrantes que, apesar de se constituirem do mesmo material, apresentaram diferentes granulometrias, segundo abordagem anterior sobre a montagem do sistema filtrante.

$\mathrm{Na}$ montagem dos filtros os materiais filtrantes foram acondicionados nas colunas de forma gradual, em camadas de $30 \mathrm{~cm}$ de espessura, sob compressão de $0,167 \mathrm{kgf} \mathrm{cm}^{-2}$ (16,35 $\left.\mathrm{kN} \mathrm{m}^{-2}\right)$, até ser atingida a altura máxima de cada tambor. Este valor de pressão foi determinado calculando-se a pressão exercida por um homem, de 50 kgf de peso apoiado em um só pé. 
Lâmina de ARS $(0,05$ m)

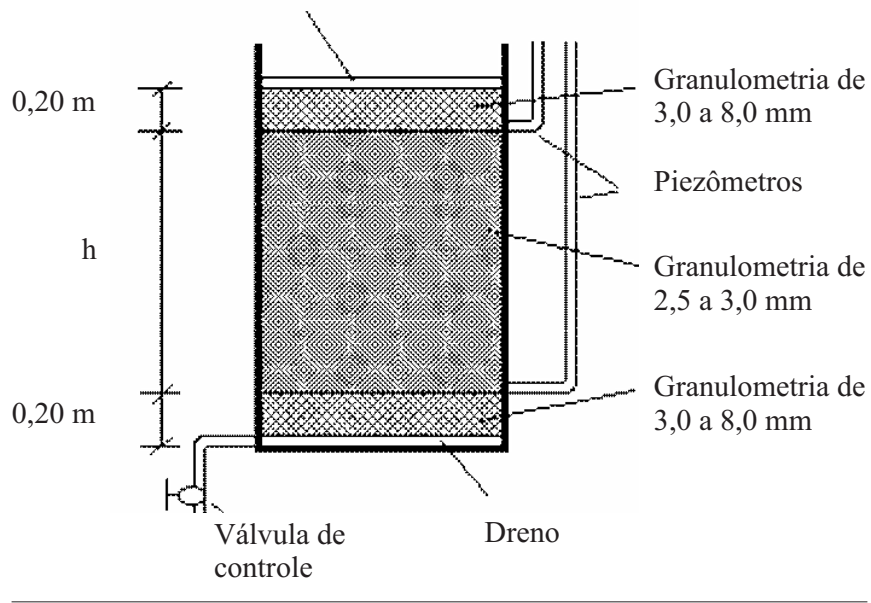

$\overline{\text { Figura 1. Esquema do sistema de filtração utilizando-se material orgânico }}$

Para minimizar o fluxo preferencial na parede interna da coluna, o material de preenchimento foi comprimido com a ponta dos dedos, em toda a periferia do filtro, durante a fase de enchimento dos mesmos. Inicialmente, as colunas de filtração foram preenchidas e operadas com bagaço de canade-açúcar, sendo os filtros operados até que perdessem a capacidade de filtração. Após a montagem dos filtros e iniciada a operação do sistema, realizou-se o monitoramento da perda de carga na camada filtrante, por meio de leituras efetuadas em régua graduada, afixada paralelamente aos piezômetros.

A água residuária de suinocultura (ARS) utilizada no experimento foi coletada em tanque de concreto de $5 \times 3 \times 3 \mathrm{~m}$, onde são estocados os efluentes gerados nas instalações da Suinocultura da UFV, e conduzida ao tanque de distribuição de onde foi transferida, por gravidade, aos filtros. A manutenção de uma lâmina permanente de 0,05 m de ARS sobre os filtros foi possível com o controle da vazão de alimentação, possibilitado com a instalação de válvulas nas tubulações de distribuição. Na saída de cada coluna de filtração também foram,, instaladas válvulas para controle do fluxo de saída e coleta de amostras do efluente.

Mantendo-se fechadas as válvulas das bases das colunas, os filtros foram, simultaneamente, saturados com ARS, até ser atingido o nível máximo de cada coluna, respectivamente 1,$00 ; 1,30 ; 1,60 ; 1,90$ e $2,20 \mathrm{~m}$ de altura; após a saturação da coluna e formação da lâmina de 0,05 m de ARS sobre a superfície do filtro, as válvulas das colunas filtrantes foram abertas, simultaneamente, permitindo o movimento do líquido nos interstícios do material filtrante contido nos filtros, sendo as colunas mantidas saturadas durante todo o período de filtração, na condição de filtro lento, procurando-se manter, por meio de controle nas válvulas, a carga hidrostática inicialmente estabelecida. A montagem e a operação dos filtros foram realizadas em triplicata para cada altura de coluna filtrante.

Durante a operação dos filtros utilizou-se uma bureta para a coleta de efluente, retirando-se amostras, a cada $10 \mathrm{~min}$, com o objetivo de se calcular a taxa de filtração do líquido e quantificar as concentrações de sólidos totais (ST) e sólidos em suspensão (SS) no efluente. No período de operação dos filtros, as águas residuárias armazenadas na caixa de distribuição foram sistematicamente revolvidas para que não houvesse sedimentação do material no fundo do recipiente.

As concentrações de ST e SS afluente e efluente de cada filtro, foram quantificadas seguindo-se metodologia recomendada pela APHA (1995), e realizadas no Laboratório de Qualidade da Água do Departamento de Engenharia Agrícola da UFV. Os dados de concentração de SS e ST do efluente (C) dos filtros foram divididos pela concentração média desses atributos no afluente $\left(\mathrm{C}_{0}\right)$, para se obter, então, os valores médios da concentração relativa $\left(\mathrm{C} / \mathrm{C}_{0}\right)$ obtida nas três repetições, com o que pode ser calculada a eficiência média desses filtros.

As concentrações de ST e SS na ARS afluente aos filtros variaram de 845 a $1.332 \mathrm{mg} \mathrm{L}^{-1}$ e 1.454 a $8.786 \mathrm{mg} \mathrm{L}^{-1}$, respectivamente, no período de operação do sistema.

$\mathrm{O}$ período de operação dos filtros foi condicionado à observação dos valores de perda de carga nos materiais filtrantes, avaliados por meio de leituras feitas nos piezômetros, sendo a operação dos filtros encerrada no momento em que a perda de carga aumentou, de tal forma a proporcionar taxa de filtração menor que $0,2 \mathrm{~L} \mathrm{~m}^{-2} \mathrm{~s}^{-1}$.

Os procedimentos estabelecidos visaram, também, à coleta de dados, o que permitiu o desenvolvimento de equações para a determinação de alguns parâmetros de projeto e operação de filtros orgânicos no tratamento da ARS. O volume de efluente coletado durante a condução dos ensaios foi convertido em lâmina filtrada proporcionando, assim, a construção de curvas, relacionando as concentrações de SS, ST e a lâmina filtrada.

Para interpretação estatística dos dados foram ajustadas equações de regressão, utilizando-se o LRP (Linear Response Plateau) e o software estatístico SAEG - Sistema de Análises Estatísticas (versão 8.0/2001), desenvolvido na Universidade Federal de Viçosa.

\section{RESULTADOS E DISCUSSÃO}

\section{Perda de carga no material filtrante}

Na Figura 2A e B estão apresentadas, respectivamente, as curvas de variação da perda de carga média nas colunas filtrantes de serragem de madeira e de bagaço de cana-de-açúcar triturado, durante o período de filtração de ARS. Com o tempo de operação do filtro, foi ocorrendo entupimento dos poros de condução do líquido, o que provocou aumento de perda de carga nas colunas filtrantes, evidenciada nas leituras da coluna líquida nos piezômetros.

O tempo de operação médio dos filtros de bagaço de cana-de-açúcar triturado foi menor que o proporcionado com o uso de filtros de serragem de madeira, em razão de ser mais rápida a obstrução dos poros e, conseqüentemente, a perda de carga nesse material. Sob este ponto de vista, o uso de filtros de serragem de madeira mostrou-se mais adequado, considerando-se o maior tempo de operação por ele proporcionado.

Pode-se verificar, após análise da Figura 2A e B, que a 
A.

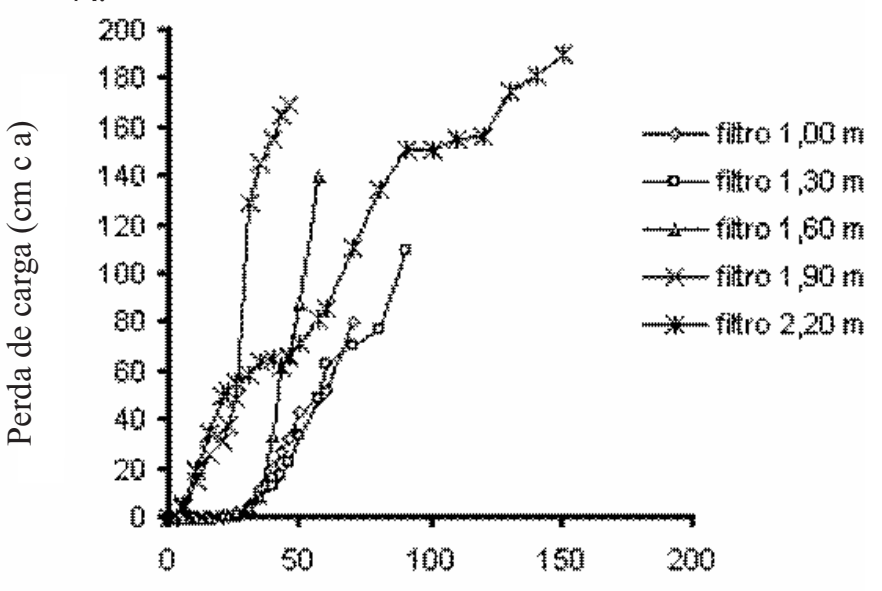

Tempo de operação dos filtros (min)

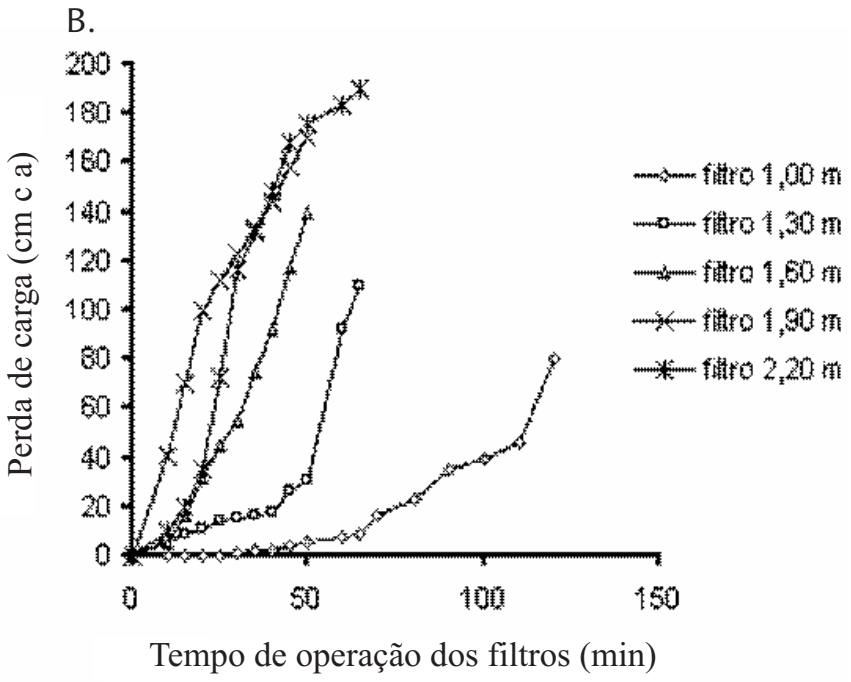

Figura 2. Perda de carga média nas colunas filtrantes de diferentes alturas, constituídas por serragem de madeira (A) e bagaço de cana-de-açúcar triturado (B), em função do tempo de operação, respectivamente

perda de carga foi crescente nos filtros constituídos por serragem de madeira e bagaço de cana-de-açúcar, ocorrendo aumento mais rápido na perda de carga nas camadas filtrantes de maior altura, tanto nos de serragem de madeira como nos de bagaço de cana-de-açúcar triturado. O maior percurso a que foi submetido o líquido percolante, foi a razão da obtenção da maior perda de carga na camada filtrante desses filtros.

Em geral, filtros de serragem de madeira proporcionaram maior tempo de operação de filtração que os de bagaço de cana-de-açúcar triturado, o que pode estar associado à sua maior porosidade ou à forma como o material se assentou no filtro, após a aplicação da ARS.

\section{Taxa de filtração}

Nas Figuras 3A e 3B estão apresentadas, respectivamente, as curvas de variação da taxa de filtração média nos filtros de serragem de madeira e bagaço de cana-de-açúcar, durante o período de operação com águas residuárias da suinocultura.

A taxa de filtração da ARS nos filtros diminuiu com o aumento no tempo de operação dos filtros de serragem de madeira e de bagaço de cana-de-açúcar, sendo o comportamento dos filtros desses materiais muito semelhantes.

No início, quando os poros dos materiais filtrantes estavam totalmente desobstruídos, a taxa de filtração era alta e a perda de carga nos filtros, baixa; com o tempo de operação dos filtros, os poros foram sendo obstruídos pelos sólidos em suspensão da ARS e, com isto, a perda de carga foi aumentando e a taxa de filtração reduzindo.

Obteve-se, após 40-50 min de operação dos filtros, maior regularidade e estabilidade na taxa de filtração dos filtros de ambos os materiais avaliados. O valor da taxa de filtração média de ARS, que pode ser considerada estável em filtros de serragem de madeira e de bagaço de cana-de-açúcar, está compreendido entre 0,2 e $0,7 \mathrm{~L} \mathrm{~m}^{-2} \mathrm{~s}^{-1}$ equivalendo a 7,2 a
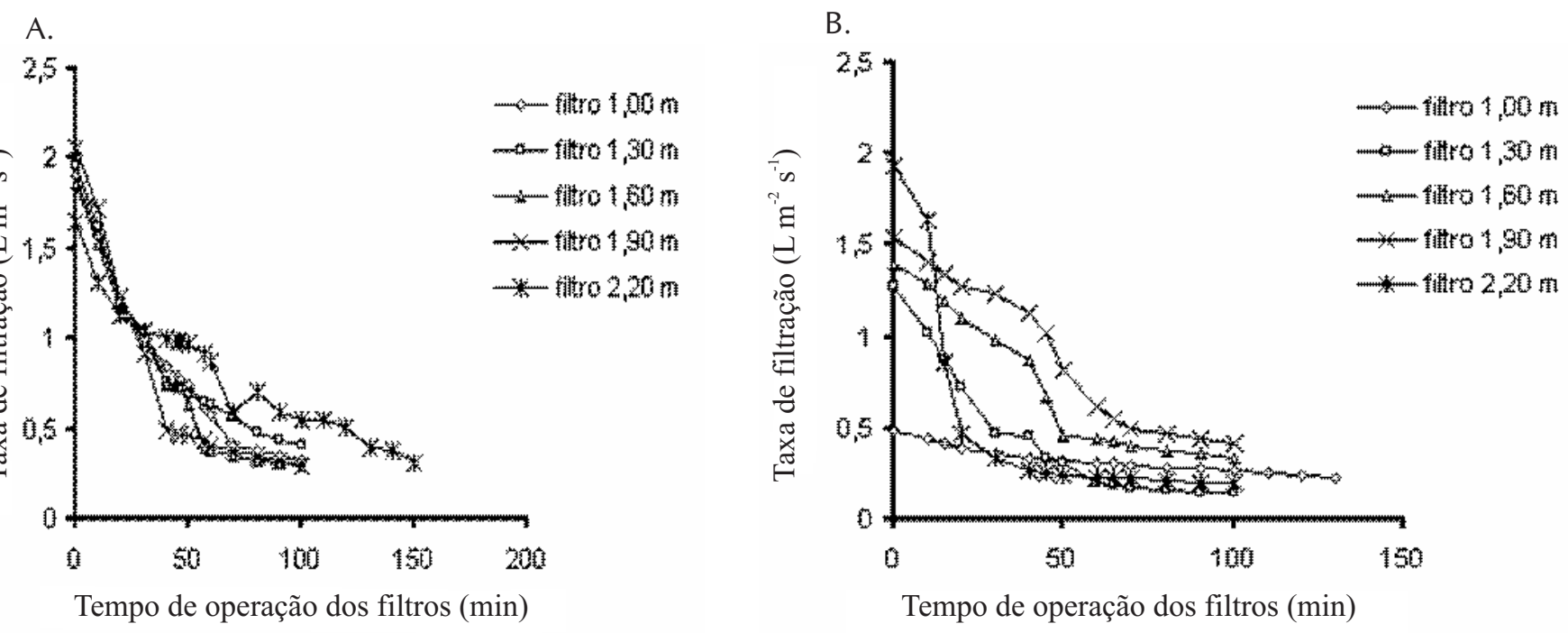

Figura 3. Variação da taxa de filtração média de ARS em serragem de madeira (A) e bagaço de cana-de-açúcar (B), durante o tempo de operação dos filtros 
25,2 $\mathrm{cm} \mathrm{h}^{-1}$. Os valores obtidos neste experimento são menores que os apresentados por Brandão et al. (2000) na filtragem de ARS em diferentes materiais orgânicos, que foram de 100 a $150 \mathrm{~cm} \mathrm{~h}^{-1}$, o que se deve à maior granulometria do material utilizado no trabalho citado, ou seja, 2,0 a 6,0 mm.

\section{Remoção de sólidos em suspensão (SS)}

Nas Figuras 4A e 4B os dados de concentração relativa $\left(\mathrm{C} / \mathrm{C}_{0}\right)$ média estão apresentados na forma de curvas de $\mathrm{C} /$ $\mathrm{C}_{0}$ (concentração relativa) de SS como função do tempo de operação do filtro de serragem de madeira e bagaço de canade-açúcar, respectivamente.

Conforme apresentado nas Figuras 4A e 4B, a concentração relativa de SS no efluente das colunas filtrantes de serragem de madeira (A) e bagaço de cana-de-açúcar (B) diminui com o tempo de operação dos filtros, isto é, com a redução da porosidade dos filtros, uma vez que SS das ARS ficaram retidos no material do filtro.

A eficiência média de remoção de SS de ARS nos filtros de serragem de madeira variou entre 90 a 99\% da concentração relativa no efluente e nos filtros de bagaço de canade-açúcar triturado a eficiência de remoção de SS da ARS variou entre 81 a $96 \%$ da concentração relativa no efluente. Comparativamente, verificou-se maior eficiência na remoção de SS em filtros de serragem de madeira que nos de bagaço de cana-de-açúcar triturado, enquanto a maior porosidade dos filtros de serragem de madeira pode ser fator de maior importância para obtenção desses resultados.

Os valores médios de concentração de SS encontrados no efluente da maioria dos filtros foram inferiores a $50 \mathrm{mg} \mathrm{L}^{-1}$, que, de acordo com Bucks et al. (1979), para este nível de concentração de SS o risco de entupimento dos gotejadores é baixo. O tempo para que o efluente dos filtros atingisse essas concentrações variou inversamente com a profundidade da coluna filtrante. Os filtros de maior altura de coluna filtrante apresentaram concentrações nesta faixa, a partir de 10-20 minutos de operação do filtro; já para os filtros de menor altura, essas concentrações foram obtidas após 6090 min de operação dos filtros.

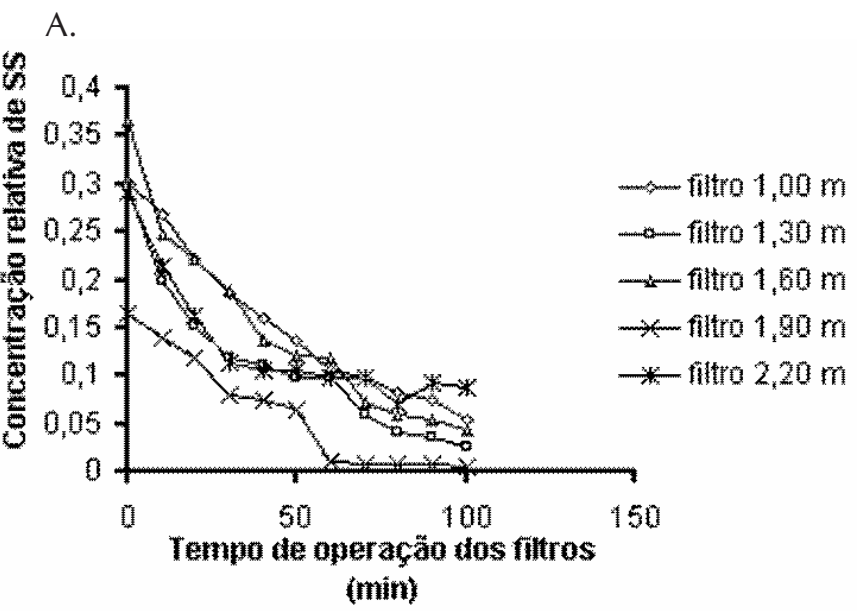

Embora se tenha observado pequenas diferenças na remoção de SS em filtros orgânicos de diferentes alturas, ao ser retirado o material filtrante dos filtros pôde-se verificar, visivelmente, que os sólidos da ARS foram retidos mesmo nos filtros de maior altura, até a profundidade máxima de 1,5 m da coluna, com o que se conclui que filtros com altura superior a 1,50 m de altura não devem proporcionar aumento na eficiência de remoção de SS.

\section{Remoção de sólidos totais (ST)}

Na Figura 5A e B estão apresentados os dados médios obtidos na forma de curvas de $\mathrm{C} / \mathrm{C}_{0}$ de $\mathrm{ST}$, como função do tempo de operação do filtro de serragem de madeira.

A eficiência média de remoção de ST da ARS nos filtros de serragem de madeira, após 60 min de operação, ficou entre 43 a $57 \%$ da concentração relativa no efluente e nos de bagaço de cana-de-açúcar, após 30 min de operação, entre 31 a $56 \%$.

Os valores de eficiência de remoção de ST obtidos podem ser considerados altos, tendo em vista que a separação física não é eficiente na remoção de sólidos dissolvidos. Parte dos sólidos dissolvidos pode ter sido retida por capilaridade na massa do material filtrante, no fenômeno de absorção. Outra parte dos sólidos dissolvidos (íons) pode ter sido retida por adsorção, por forças eletrostáticas, junto às partículas dos materiais filtrantes, conforme observaram Brandão et al. (2000).

A Tabela 1 apresenta as equações de regressão ajustadas para concentração relativa $\left(\mathrm{C} / \mathrm{C}_{0}\right)$ média de SS e ST como variável dependente do tempo de operação dos filtros, respectivamente para a serragem de madeira e para o bagaço de cana-de-açúcar.

$\mathrm{O}$ ajuste de equações lineares aos dados obtidos de concentração de SS e de ST em função do tempo indicou que, inicialmente, a eficiência na remoção de SS e ST da ARS aumentou na mesma proporção em que os poros foram sendo obstruídos; posteriormente, verificou-se tendência de estabilização do processo, ocasião em que a eficiência se manteve aproximadamente constante.

Nas condições em que o experimento foi conduzido, o

$$
\text { B. }
$$

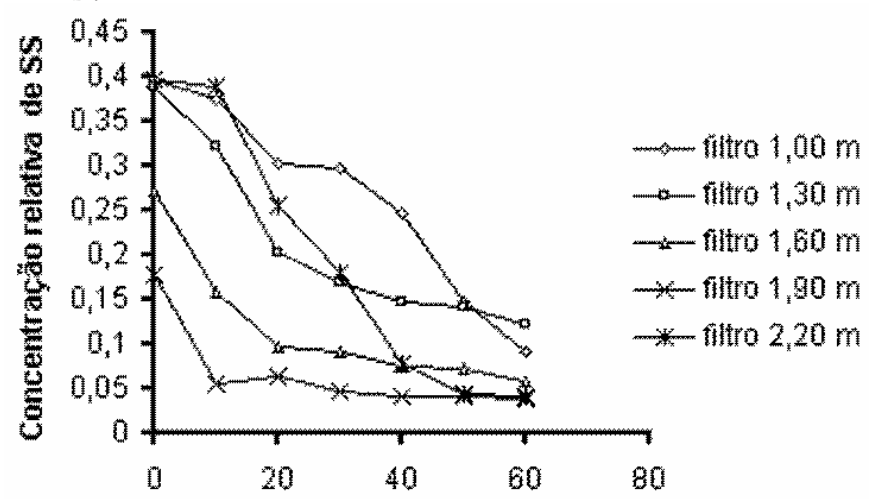

Tempo de operação dos fittros (min)

Figura 4. Concentração relativa $\left(C / C_{0}\right)$ média de SS no efluente dos filtros de serragem de madeira $(A)$ e bagaço de cana-de-açúcar (B), em função do tempo de operação do sistema 
A.

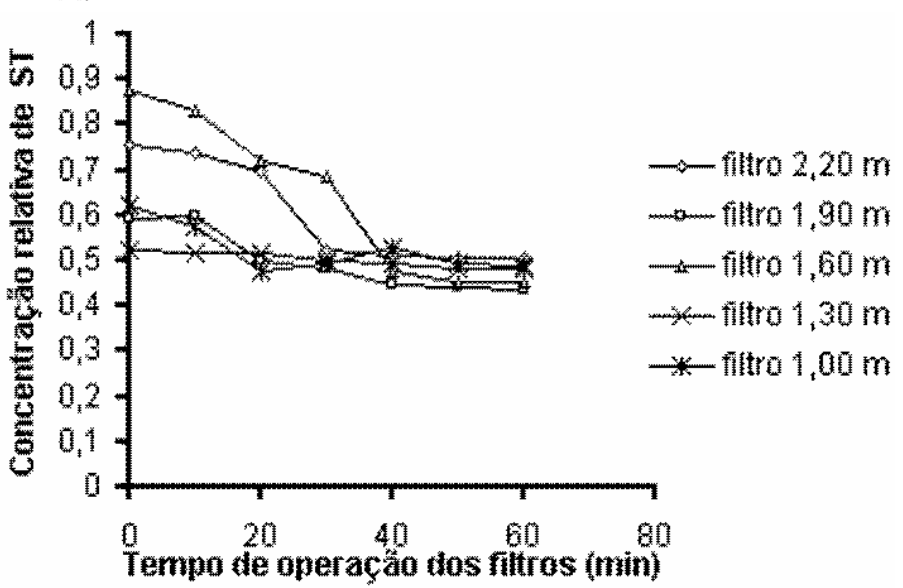

B.

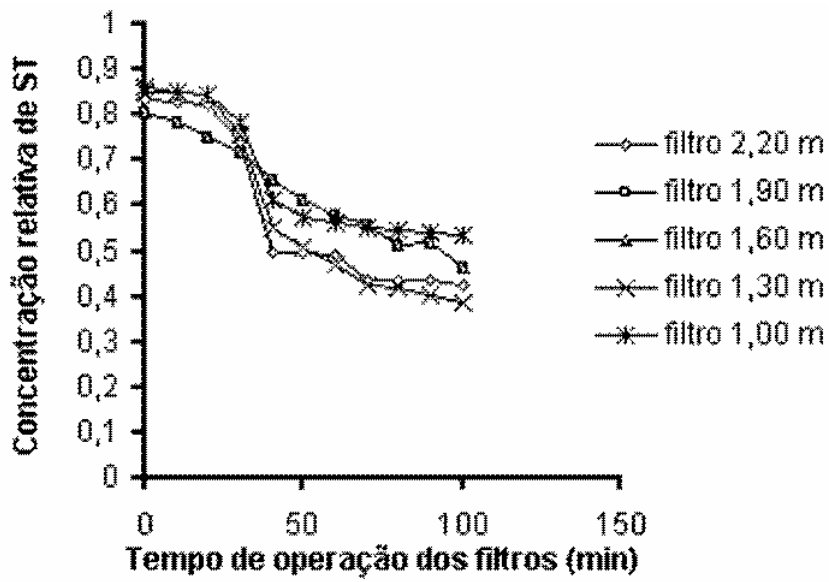

Figura 5. Concentração relativa $\left(C / C_{0}\right)$ média de ST no efluente dos filtros de serragem de madeira $(A)$ e bagaço de cana-de-açúcar (B), em função do tempo de operação do sistema

Tabelas 1. Equações de regressão ajustadas para concentração relativa $\left(\mathrm{C} / \mathrm{C}_{0}\right)$ média de SS e ST, como variáveis dependentes do tempo $(\mathrm{t})$ de operação dos filtros de serragem de madeira e bagaço de cana-de-açúcar

\begin{tabular}{|c|c|c|c|}
\hline Filtro & Equação & $\begin{array}{l}\text { Relação } \\
\text { C/CO(1) }\end{array}$ & $\begin{array}{c}\text { Tempo de } \\
\text { operação(2) (min) }\end{array}$ \\
\hline \multicolumn{4}{|c|}{ Serragem de madeira } \\
\hline \multicolumn{4}{|c|}{ Sólidos em Suspensão (SS) } \\
\hline $1,00 \mathrm{~m}$ & $S S=0,291-0,003 t$ & 0,071 & 70,00 \\
\hline $1,30 \mathrm{~m}$ & $S S=0,239-0,003 t$ & 0,034 & 90,00 \\
\hline $1,60 \mathrm{~m}$ & $S S=0,316-0,004 t$ & 0,057 & 57,00 \\
\hline $1,90 \mathrm{~m}$ & $S S=0,159-0,002 t$ & 0,008 & 46,00 \\
\hline $2,20 \mathrm{~m}$ & $S S=0,283-0,006 t$ & 0,094 & 150,00 \\
\hline \multicolumn{4}{|c|}{ Sólidos Totais (ST) } \\
\hline $1,00 \mathrm{~m}$ & $\mathrm{ST}=0,904-0,006 \mathrm{t}$ & 0,554 & 70,00 \\
\hline $1,30 \mathrm{~m}$ & $\mathrm{ST}=0,917-0,007 \mathrm{t}$ & 0,499 & 90,00 \\
\hline $1,60 \mathrm{~m}$ & $\mathrm{ST}=0,912-0,006 \mathrm{t}$ & 0,577 & 57,00 \\
\hline $1,90 \mathrm{~m}$ & $\mathrm{ST}=0,811-0,003 \mathrm{t}$ & 0,462 & 46,00 \\
\hline $2,20 \mathrm{~m}$ & $\mathrm{ST}=0,892-0,007 \mathrm{t}$ & 0,431 & 150,00 \\
\hline \multicolumn{4}{|c|}{ Bagaço de cana-de-açúcar } \\
\hline \multicolumn{4}{|c|}{ Sólidos em Suspensão (SS) } \\
\hline $1,00 \mathrm{~m}$ & $S S=0,405-0,005 t$ & 0,196 & 120,00 \\
\hline $1,30 \mathrm{~m}$ & $S S=0,398-0,009 t$ & 0,146 & 65,00 \\
\hline $1,60 \mathrm{~m}$ & $S S=0,270-0,001 t$ & 0,078 & 50,00 \\
\hline $1,90 \mathrm{~m}$ & $\mathrm{SS}=0,179-0,001 \mathrm{t}$ & 0,047 & 50,00 \\
\hline $2,20 \mathrm{~m}$ & $S S=0.429-0,008 t$ & 0,043 & 65,00 \\
\hline \multicolumn{4}{|c|}{ Sólidos Totais (ST) } \\
\hline $1,00 \mathrm{~m}$ & $\mathrm{ST}=0,624-0,005 \mathrm{t}$ & 0,496 & 120,00 \\
\hline $1,30 \mathrm{~m}$ & $\mathrm{ST}=0,526-0,001 \mathrm{t}$ & 0,482 & 65,00 \\
\hline $1,60 \mathrm{~m}$ & $\mathrm{ST}=0,908-0,009 \mathrm{t}$ & 0,453 & 50,00 \\
\hline $1,90 \mathrm{~m}$ & $\mathrm{ST}=0,607-0,004 \mathrm{t}$ & 0,444 & 50,00 \\
\hline $2,20 \mathrm{~m}$ & $\mathrm{ST}=0,789-0,007 \mathrm{t}$ & 0,508 & 65,00 \\
\hline
\end{tabular}

2 Tempo de operação do filtro com ARS até obtenção de taxa de filtração menor que $0,2 \mathrm{~L} \mathrm{~m}^{-2} \mathrm{~s}^{-1}$

volume de ARS filtrado nos filtros de serragem de madeira e de bagaço de cana-de-açúcar triturado, com 0,264 $\mathrm{m}^{2}$ de seção transversal, variou entre 3.600 a $5.500 \mathrm{~L}$ filtro-$^{-1}$, até que ocorresse significativa obstrução dos poros, concorrendo para a obtenção de taxas de filtração menores que $0,3 \mathrm{~L} \mathrm{~m}^{-2} \mathrm{~s}^{-1}$, correspondente à capacidade de filtragem de água residuária gerada, por dia, por lotes de 360 a 550 suínos, admitindo-se que o gasto médio de água para higienização das baias é de $10 \mathrm{~L}_{\text {suíno }}{ }^{-1} \mathrm{~d}^{-1}$. Em $1 \mathrm{~m}^{2}$ de área de seção transversal, os volumes filtrados poderiam ser multiplicados por quatro. Esses resultados indicam grande viabilidade no uso desses filtros, ainda que seu tempo de operação tenha sido relativamente curto.

Para facilitar a operação e o manejo dos filtros, considera-se de fundamental importância que seja contemplada, no projeto de sistemas de tratamento de ARS, a construção de um tanque de armazenamento da água residuária gerada diariamente, uma vez que, além de possibilitar o tratamento primário da ARS (remoção de parte dos sólidos por sedimentação), a presença do tanque possibilita a operação dos filtros sob carga menos variável e a troca, sempre que se fizer necessária, do material filtrante.

\section{CONCLUSÕES}

1. A eficiência de retenção de sólidos em suspensão pelo material filtrante aumentou com o tempo de uso, fato este ocasionado pela obstrução gradativa dos poros provocada pela percolação de ARS nas colunas filtrantes.

2. Os filtros de serragem de madeira mostraram-se mais eficientes na remoção de SS, obtendo-se remoções médias de 90 a 99\%, e os filtros de bagaço de cana-de-açúcar foram ligeiramente superiores na remoção de ST, com remoções médias de 50 a $56 \%$.

3. Com o aumento da altura da coluna filtrante não se observou aumento na eficiência dos filtros na remoção de sólidos em suspensão; assim, recomenda-se a utilização de filtros com até $1,5 \mathrm{~m}$ de altura, na taxa de compressão utilizada neste trabalho.

4. O tempo de operação médio dos filtros variou de 60 a 100 min, suficiente para o tratamento de 3.600 a $5.500 \mathrm{~L}$ de ARS. 


\section{LITERATURA CITADA}

APHA - American Public Health Association - Standard methods for the examination of water and wastewater. New York: APHA, WWA, WPCR, 19 ed., 1995.

Brandão, V. S.; Matos, A. T.; Martinez, M. A. ; Fontes, M. P. P. Tratamento de águas residuárias da suinocultura utilizando-se filtros orgânicos. Revista Brasileira de Engenharia Agrícola e Ambiental, Campina Grande, v.4, n.3, p.327-333, 2000.

Bucks, D. A.; Nakayama, F. S.; Gilbert, R. G. Trickle irrigation water quality and preventive manitenance. Agricultural Water Management, Amsterdam, v.2, p.149-162, 1979.

Leon, S. G.; Cavallini, J. M. Tratamento e uso de águas residuárias; tradução de: Treatment end use of wastewater. Campina Grande: UFPB, 1999. 110p.

Lo Monaco, P. A.; Matos, A. T.; Jordão, C. P.; Cecon, P. R.; Martinez, M. A. Influência da granulometria da serragem de madeira como material filtrante no tratamento de águas residuárias. Revista Brasileira de Engenharia Agrícola e Ambiental, Campina Grande, v.8, n.1, p.116-119, 2004
Lo Monaco, P. A.; Matos, A. T.; Martinez, M. A.; Jordão, C.P. Eficiência de materiais orgânicos filtrantes no tratamento de águas residuárias da lavagem e despolpa dos frutos do cafeeiro. Engenharia na Agricultura, Viçosa, v.10, n.1-4, p.4047, 2002

Magalhães, M. A. Parâmetros para projetos e operação de filtros orgânicos utilizados no tratamento de águas residuárias de suinocultura. Viçosa: UFV, 2002. 103p. Dissertação Mestrado

Matos, A. T.; Sediyama, M. A. N.; Freitas, S. P.; Vidigal, S. M.; Garcia, N. C. P. Características químicas e microbiológicas do solo influenciadas pela aplicação de dejeto líquido de suínos. Revista Ceres, Viçosa, v.44, n.254, p.399410, 1997.

Povinelli, J.; Martins, F. Pesquisa sobre a eficiência de filtros lentos em unidades piloto. In: Congresso Brasileiro de Engenharia Sanitária, 7, 1973, Salvador. Anais... São Carlos: EESC/USP, 1973. 20p. 